\title{
O Caráter Provisório do Sujeito na Ficção DE JoÃo GILBERTO Noll
}

\section{The provisional character of the subject in the fiction of João Gilberto Noll}

\author{
Ricardo da Silva Sobreira*
}

\begin{abstract}
Não importando o ponto de vista filosófico em que nos situemos hoje: o caráter errôneo do mundo onde acreditamos viver é a coisa mais firme e segura que nosso olho ainda pode apreender.

Nietzsche, Além do bem e do mal, 2005, p. 38.
\end{abstract}

o problema da identidade humana tem sido motivo de intensa reflexão em diferentes campos do conhecimento, sobretudo, no período histórico atual, em que observamos ocorrerem profundas transformações históricas, grandes fenômenos sociais, a sofisticação tecnológica e uma nova configuração do capitalismo no ocidente, chamado por Ernest Mandel de "capitalismo tardio" (JAMESON, 2000, p. 22-23). Esse cenário contemporâneo tem abalado as antigas formas de identidade, como, por exemplo, a do "sujeito cartesiano", concebido como um "sujeito racional, pensante e consciente, situado no centro do conhecimento" (HALL, 2002, p. 27), e, por essa razão, fornecido uma arena propícia para o surgimento não de uma identidade centrada, unificada e coerente, mas de identidades fragmentárias, instáveis e em permanente construção.

Nesse contexto de "problematização, mais do que da negação, de todos os modelos e parâmetros" (VILLAÇA, 1996, p. 7), as teorias pósmodernas têm provocado o desaparecimento gradual de noções unitárias de discurso, conhecimento e, por conseguinte, de sujeito como "uma idéia particular, uma figuração concreta da história” (HASSAN, 1987, p. 53). As

Doutorando em Letras pela UNESP 
práticas artísticas, nessa mesma corrente, movimentam uma série de formas discursivas indeterminadas, lúdicas, provisórias, abertas e irônicas (HASSAN, 1987, p. 93). Um desses procedimentos discursivos é a indeterminação (HASSAN, 1987, p. 92), termo recentemente incorporado ao vocabulário crítico, além de outros processos que se relacionam ou se confundem com ela como a ambigüidade, a destotalização, a descontinuidade, a disjunção, entre outros.

A indeterminação consiste (talvez) na (simulação de uma) impossibilidade ou dificuldade experimentada pelo narrador do texto literário de manipular de modo rigoroso as unidades significativas do mundo imaginário da obra literária e de fornecer uma visão totalizante desses mesmos elementos, capaz de suscitar o completo preenchimento concretizador do leitor. Dessa maneira, o narrador deixa de constituir-se como instância confiável incumbida da função de representar de maneira totalizante os dados narrados e passa a protagonizar seu próprio colapso como eixo estável responsável por apreender e dispor de maneira rigorosa o universo ficcional projetado pelo texto.

Umberto Eco, no livro Obra aberta: forma e indeterminação nas poéticas contemporâneas, argumenta que essas estratégias têm dado a tônica de numerosos produtos culturais contemporâneos. Segundo o pesquisador, a arte recente tende a aceitar e tentar dar forma à provocação do acaso, do ambíguo, do provável revelado pelo desenvolvimento de hipóteses teóricas como as da indeterminação, da probabilidade estatística, dos modelos explicativos provisórios e variáveis. Os artistas, nessa mesma esteira, têm buscado mapear com seus artefatos estéticos essa "desordem". Porém, não se trata de uma desordem incurável, a "derrota de toda possibilidade ordenadora" (ECO, 1969, p. 23), mas de uma desordem fecunda, que visa provocar a ruptura de uma "ordem tradicional", unívoca e fechada, e estimular um tipo de fruição da obra de arte que é, ao mesmo tempo, inventiva e aberta (ECO, 1969, p. 41-42).

Essa desestabilização do narrador na prosa recente, em especial, o narrador em primeira pessoa, como centro organizacional da diegese, pode ser interpretada como uma tentativa de representar artisticamente os entraves da vida cotidiana moderna que levam o homem contemporâneo a experimentar sucessivas "crises de identidade", que, no entender do pesquisador Stuart Hall, têm sido vivenciadas pelo sujeito pós-moderno em face dos angustiantes deslocamentos e mudanças estruturais das sociedades ocidentais desde as décadas finais do século XX (HALL, 2002, p. 9).

A pesquisadora Marlise Vaz Bridi, em Modernidade e pósmodernidade na ficção portuguesa contemporânea, também reconhece na 
constante busca do novo e, sua "dialética conseqüência, a crise de identidade", desdobramentos dialógicos dos elementos unanimemente indicados como característicos da contemporaneidade, "essa movediça conceituação temporal" (BRIDI,1999, p. 4). Esse contexto de incertezas no tocante a noções antes consideradas inequívocas pode, portanto, ser associado à pósmodernidade. Porém, como discorrer sobre "pós-modernidade" se, conforme questionou a pesquisadora Maria Elisa Cevasco (2001, p. 25), este termo parece ser "um ninho de conflitos e indecisão semântica"?

O crítico Terry Eagleton, em The Illusions of Postmodernism (1996), fornece uma delimitação do termo ao indicar que a pós-modernidade é um fenômeno artístico e sócio-cultural, que, devido às transformações históricas ocorridas no Ocidente e ao surgimento de um novo tipo de capitalismo aliado à sofisticação tecnológica e ao triunfo do consumismo, tende a desafiar as normas preconizadas pelo Iluminismo e a ver o mundo como um conjunto de culturas desunificadas, contingente, instável, indeterminado, e que, por essa razão, suspeita de "noções clássicas de verdade, razão, identidade e objetividade, [bem como] da idéia de progresso ou emancipação universais, das estruturas únicas, grandes narrativas ou bases definidas de explicação" (EAGLETON, 1997, p. vii) ${ }^{1}$.

Dentro dessa perspectiva, a pós-modernidade problematizaria os valores e preceitos defendidos pelos pensadores vinculados ao Iluminismo, um "estilo de pensamento voltado para o racional, o claro, o regular, o verossimil" (BOSI, 1999, p. 55). Por esse motivo, podemos observar que o "eu" coerente, equilibrado e consciente, ou o "sujeito cartesiano" (HALL, 2002, p. 13) típicos da Ilustração, sofrem um acentuado declínio no século $\mathrm{XX}$, ocasionando, sobretudo no final desse século, o aparecimento de um sujeito problemático e contraditório, incapaz de fixar uma "ancoragem estável no mundo social" (HALL, 2002, p. 1).

Esse "novo" sujeito, de caráter provisório e indefinido, tem sido manifestado no âmbito da obra de arte literária por meio de textos repletos de áreas elípticas, descontínuas e, sobretudo, indeterminadas. Tomemos como exemplo o microconto "Refugiado", do escritor gaúcho João Gilberto Noll, coligido no livro Mínimos, múltiplos, comums (2003):

Estava eu sendo procurado. Talvez tudo não passasse de um engano. Se eles não fossem o que eu pensava? Ou se eu não fosse a figura que deveriam seguir? A dona que me atendia no hotel em São Borja parecia enfim alguém completamente negligente diante do autor do artigo.

$$
\text { Todas as traduções utilizadas neste texto são de autoria e de responsabilidade do }
$$


que eu pudesse ser. Fui para o quarto com inegável alívio. "Provisório, será?" No espelho do banheiro sondei lentamente minha imagem como se foragida de minha identidade. Um refugiado de suas próprias pistas. Apenas uma face absorta na desatenção plena do banheiro, uma face já sem traços, isso, transparente, resistindo a seu modo, ali, sob o perolado instante dos ladrilhos (NOLL, 2003, p. 322).

Composto por pouco mais de cem palavras, esse texto apresenta um ser ficcional que, perseguido por terríveis vilões ("eles”) ou apenas atormentado por seus próprios construtos mentais, comporta-se como um foragido angustiado, desprovido de uma identidade estável e sem contornos definidos.

Dadas as estratégias de extrema concisão do conto, sobre as quais nos deteremos de modo mais pormenorizado adiante, este se apresenta como uma narrativa porosa, repleta de incompletudes e indeterminações. Esse texto, portanto, recusa-se a fornecer respostas unívocas para questões básicas do enredo como, por exemplo, quem é o protagonista, ou o que ele faz e, se desenvolve algum tipo de ação, quando isso ocorre e por que a pratica?

Encontramos apenas respostas precárias para essas questões no texto: Há uma personagem, provavelmente do sexo masculino ("procurado"), que parece estar fugindo (daí o título do conto ser "Refugiado"), perseguido por outros seres que, de certa forma, ameaçam-no. Dessa forma, ainda que o texto faça referência (talvez) a um hotel na cidade rio-grandense de São Borja, não há uma representação totalizante do universo ficcional projetado pelo texto. "Refugiado", bem como os demais contos da coletânea, não desenvolve discurso de ordem explicativa e não parece regido por um nexo de causalidade rigoroso. As referências espaciais e temporais são extremamente vagas e as personagens perambulam por esses ambientes difusos como flaneurs sem destino.

Contudo, o elemento em torno do qual a tensão parece mais mobilizada nesse texto em particular é a questão da identidade da personagem. Seu status de sujeito é representado de uma maneira bastante debilitada. A própria personagem se dá conta de sua instabilidade e provisoriedade ao examinar seu reflexo no espelho: "sondei lentamente minha imagem como se foragida de minha identidade. Um refugiado de suas próprias pistas" (NOLL, 2003, p. 322). Essa passagem sugere não apenas a perda de referenciais geográficos e sociais da personagem, mas a impossibilidade do sujeito de recompor os traços de sua própria personalidade e de identificar em sua imagem traços de reconhecimento de algo familiar ou comum, instaurando, dessa maneira, uma dificuldade de representação 
de si mesmo.

Como o narrador não fornece uma visão absolutizante dos fatos narrados em seu instante ficcional, encenando, desta forma, a sua própria incerteza e desconforto por meio das omissões no tocante às referências de caráter espacial, temporal e até mesmo causal, o texto não comporta um fechamento rigoroso. Os acontecimentos descritos pelo narrador são indeterminados, envoltos por uma atmosfera contingente e confusa. Dessa maneira, podemos perceber que o narrador protagoniza seu próprio colapso como eixo estável do relato, pois se mostra incapaz de conferir um sentido à experiência vivenciada por ele mesmo e, deste modo, fornece apenas traços inconsistentes acerca de quem é realmente e do que está fugindo.

Podemos então inferir que o narrador, por meio de seu relato indeterminado, projeta sua própria crise de identidade de um modo angustiante, pois, "procurado" por alguém, cuja ameaça parece incerta, e sentindo-se "refugiado de suas próprias pistas", busca um abrigo provisório em um hotel onde se esconde, anônimo e confuso (NOLL, 2003, p. 322), isto é, o narrador parece não encontrar referenciais estáveis para ancorar-se no meio social em que vive. Kathryn Woodward, no ensaio "Identidade e diferença: uma introdução teórica e conceitual", postula que "a identidade é, na verdade, relacional, e a diferença é estabelecida por uma marcação simbólica relativamente a outras identidades" (SILVA, 2005, p. 14).

Como o narrador não sabe quem são os "outros" que o perseguem, não tem muita noção de onde está, bem como parece ignorar a razão pela qual está fugindo, não consegue, portanto, estabelecer parâmetros razoáveis para a constituição de sua própria identidade. Conforme sugere o texto, os "outros" que o procuram não possuem uma identidade minimamente palpável. o próprio narrador atenta para a inconsistência dessa ameaça ao confessar que "talvez tudo não passasse de um engano. Se eles não fossem o que eu pensava?" (NOLL, 2003, p. 322, grifo nosso).

Várias questões permanecem em aberto no texto como, por exemplo, em que "eles" diferem do "eu" que fala no texto? Quais os traços que "eles" apresentam e que, por essa razão, constituem uma ameaça para o "eu"? E, sobretudo, quais os traços contidos no "eu" para que este se sinta oprimido diante de seus opressores e precise refugiar-se? Em decorrência de sua dificuldade em fornecer respostas para esses questionamentos e, acima de tudo, não conseguir marcar de forma simbólica qual a identidade de seus possíveis perseguidores, o narrador enfrenta grandes dificuldades em marcar simbolicamente a sua própria identidade.

Contudo, a crise de identidade vivenciada pelo protagonista do microconto de João Gilberto Noll não se restringe ao plano do conteúdo 
projetado pelo texto, mas é construído de modo meticuloso por meio do trabalho com a palavra. O crítico João Barrento, em prefácio do livro de poemas de Ana Hatherly, observa que grande parte da arte contemporânea tenta plasmar "o mundo na própria linguagem, e não só por meio dela" (BARRENTO, 1999, p. 18). Deste modo, vejamos a seguir quais são as técnicas narrativas empregadas por Noll para representar no seio da linguagem o caráter provisório do sujeito pós-moderno.

\section{A Ruptura com os Modos Tradicionais de Representação do SUJEITO}

Anatol Rosenfeld, em Literatura e personagem, observa que, ao contrário dos seres e objetos detectáveis na realidade empírica, caracterizados por uma "multiplicidade infinita" de determinações e por seu caráter "inefável" (ROSENFELD, 1998, p. 32), a obra de arte literária, constituída por "objectualidades puramente intencionais" projetadas pela camada verbal (ROSENFELD, 1998, p. 15-16) sempre apresentará vastas regiões indeterminadas, em virtude de as personagens, por exemplo, serem sempre configurações esquemáticas (ROSENFELD, 1998, p. 33). Dessa maneira, nos textos convencionais, o leitor tende a não notar as zonas indeterminadas, pois "atualiza" o que é dado pela obra e "ultrapassa" os dados projetados pelo texto, encobrindo essas áreas de indeterminação por meio do que Rosenfeld (1998, p. 14) chama de "imaginação concretizadora do apreciador".

No entanto, essa atividade de preenchimento, em textos como "Refugiados", de João Gilberto Noll, é dificultada ou mesmo inviabilizada em decorrência do emprego de estratégias narrativas minimalistas como o desbastamento da sintaxe, a fragmentação e a descontinuidade do relato, a tessitura elíptica e indeterminada do enredo e, sobretudo, da erosão do narrador como centro organizador da percepção. Devido ao fato de a indeterminação apresentar variados "disfarces", como, por exemplo, formas parciais, descontínuas, lúdicas, auto-reflexivas, entre outras, o crítico Ihab Hassan (1987, p. 92) prefere usar o termo "indeterminações".

Com base em nossos estudos sobre o minimalismo literário, tendência artística cuja emergência ocorreu nas décadas finais do século $\mathrm{XX}$, nos Estados Unidos, caracterizada pela extrema brevidade, pelo emprego de uma sintaxe despojada, paratática, pela postura impassível do narrador que, muitas vezes, restringe-se a enfocar de forma externa as situações e as personagens, recusando-se lhes investigar a alma, bem como pela omissão de elementos supérfluos (BARTH, 1995, p. 65; MCCAFFERY, 1988, p. 11641166; BIRKERTS, 2001, p. 68), percebemos que essas estratégias narrativas 
dificultam uma total interação do apreciador com os dados do universo imaginário. Em geral, essas histórias minimalistas são muito condensadas, destituídas de fechamentos, explicações, de noções de causalidade natural, pois, em vez de narrar uma história de maneira convencional, a obra de arte minimalista prefere sugerir pequenos conflitos, fornecendo pistas sutis, pequenas indicações para que o leitor infira acerca de seu sentido. Dada a estrutura porosa, elíptica e paratática desses textos, podemos, portanto, notar que essas técnicas minimalistas colaboram para a instauração de indeterminações no texto literário.

Nas pequenas histórias que compõem Mínimos, múltiplos, comuns, o escritor brasileiro João Gilberto Noll parece ter deixado o estilo torrencial, barroco (TREECE, 1992, p. 13; NINA, 2002, p. 2) de um romance como A fúria do corpo (1981), para investir em um estilo mais contido, que, executado com maior intensidade, resulta em narrativas mais simplificadas e diretas, como Rastros de verão (1986) e Hotel Atlântico (1989), além da coletânea já mencionada.

Embora de maneiras e intensidades distintas, podemos notar que as narrativas coligidas em Mínimos, múltiplos, comuns projetam um universo imaginário contingente, repleto de lacunas e silêncios que limitam o leitor em estabelecer a significação do que está sendo articulado nas histórias. $O$ enredo, por não se constituir uma representação totalizante, mas uma justaposição de acontecimentos diminutos e aleatórios, dificulta o estabelecimento de leituras unívocas e suscita uma pluralidade de perspectivas. Além disso, vários dos textos reunidos em Mínimos, múltiplos, comuns dificultam ou mesmo impossibilitam o preenchimento imaginário do apreciador, pois, o narrador, instância teleológica responsável por articular os fatos e situações narrados é, muitas vezes, omisso no tocante à causalidade e reticente no que diz respeito ao detalhe e, portanto, é apenas capaz de apresentar uma visão subjetiva e, portanto, parcial dos dados narrados. E muito dessa impressão é garantida pelos trechos escritos em estilo paratático.

A agonia das personagens e a estrutura quebrada e descontínua das experiências humanas flagradas por esses "instantes ficcionais" (BRASIL, 2003, p. 1) são sugeridas, na economia do texto de Noll, pelo emprego predominante de uma sintaxe paratática. Em diversos dos textos coligidos em Mínimos, múltiplos, comuns, as orações são meramente justapostas, como pequenas parcelas de realidade, sem conexões rigorosas entre esses elementos. Vejamos, como forma de exemplificação, o microconto "Sangue no Guaíba": 


\begin{abstract}
Aquele sangue nas mãos que eu devia lavar ali, no Guaíba. Se não, desconfiariam. Do quê, nem eu mesmo sabia. Lembro que, pouco antes, num lance gratuito, imaginara que se tivesse ficado em casa estaria em melhor situação. Foi só então que vi as mãos cobertas de sangue. Olhei o rio, tentando escapar da circunstância. Apesar do estado das águas, entrei até os joelhos. E agora só restava assobiar. A melodia imprecisa, o dia ameno, parecendo ileso. Pouco a pouco o assobio amortecia tudo. A noite logo mais me acolheria. Para que sonhar? (NOLL, 2003, p. 107).
\end{abstract}

Nesse texto, percebemos que o narrador-personagem encontra-se no auge de uma situação tensa que nem ele próprio consegue entender. A utilização da sintaxe paratática colabora para criar esse clima de incompreensão, pois não há uma ligação causal entre os dados narrados: por que as mãos do protagonista estão empapadas de sangue? Ele cometeu um homicídio? Será que as mãos ensangüentadas são os traços de um crime? Será por isso que ele deve lavá-las para que não desconfiem dele?

O texto minimalista não se preocupa em explicar nada, em desenvolver discursos que tornem clara qual a relação entre os fatos do universo imaginário. Não há um impulso rigoroso no sentido de criar nexos de causalidade, de organizar a história em começo, meio e fim. Praticamente, nem há uma história a ser contada. $O$ texto apenas apresenta pequenas situações aleatórias e, a partir daí, entra em cena uma série de técnicas de sugestão de possíveis significados. Mas não há caminhos definidos para a interpretação, pois o texto não comporta respostas unívocas, determinadas. o narrador nega-se a plasmar em seu relato uma ordem que é incapaz de encontrar na complexidade dos dados apresentados pelo real. Deste modo, sua experiência é relatada de modo indeterminado, fragmentário e aberto.

As orações paratáticas, portanto, colaboram para a sugestão da descontinuidade da história, para reavivar as sensações de desorientação e de incerteza projetadas pelo texto por meio de um enfoque minucioso na plasticidade dos mínimos gestos e pensamentos do protagonista: "Foi só então que vi as mãos cobertas de sangue. Olhei o rio, tentando escapar da circunstância. [...] A melodia imprecisa, o dia ameno, parecendo ileso. Pouco a pouco o assobio amortecia tudo. A noite logo mais me acolheria" (NOLL, 2003, p. 107). As ações são relatadas em pequenos quadros isolados, como fotogramas dispostos um ao lado do outro, porém, sem uma relação explicativa entre esses elementos.

Como sabemos, a parataxe constitui-se uma modalidade de organização sintática na qual as orações são desprovidas de conexões 
rigorosas, ou seja, as orações são meramente justapostas. O termo "parataxe", de acordo com o gramático Luiz Antonio Sacconi (1994, p. 77), surge a partir da junção de duas palavras de origem grega: o prefixo "pará", que significa "ao lado"; e o radical "táxis", que quer dizer "arranjo, ordem, classificação" (SACCONI, 1994, p. 95). A partir daí, o autor assume que a parataxe ("arranjar ao lado de") "designa a construção sintática em que as orações se ligam por justaposição, e não por conetivos" (SACCONI, 1994, p. 329). Sacconi (1994, p. 329-331) observa ainda que a parataxe é muitas vezes confundida com coordenação assindética, porém, é possível ocorrerem relações de subordinação paratáticas como, por exemplo, em "Viverás muito tempo, é claro".

No livro Análise do texto literário: orientaçóes estilísticas, o pesquisador Antônio Manoel dos Santos Silva discute de modo detalhado as distinções entre parataxe e hipotaxe. Para o autor, a parataxe abrange as formas de coordenação, ao passo em que a hipotaxe está mais relacionada às relações oracionais de subordinação (SILVA, 1981, p.121). Defendendo um ponto de vista contrário ao de Sacconi, Silva (1981, p. 122, grifo nosso) elucida que "haverá parataxe quando sentenças e frases complexas estiverem ligadas por conjunções aditivas e pelas alternativas "ou", "ora... ora", "já... já", ou então quando estiverem alinhadas sem o liame das conjunções, salvo os casos de reduções por particípio, por gerúndio e por infinitivo [...]".

Não obstante a questão seja complexa, cabe ressaltar que Antônio Manoel dos Santos Silva não se restringe às discussões da parataxe no tocante aos seus aspectos formais de organização, mas expande sua angulação teórica ao nível da produção de sentidos do texto. Segundo o pesquisador, uma obra que privilegia a relação paratática entre as orações tende a conferir um tom mais emotivo ao relato, instaurando uma espécie de "visão sentimental do mundo". Silva (1981, p. 122) explicita essa noção nos seguintes termos:

\footnotetext{
[Em um texto cuja organização paratática fosse predominante] a relação conceitual se afrouxa, ganhando relevo uma expressão em que o afetivo supera a representação cognitiva ou puramente intelectiva. Com essa organização, que domina na linguagem falada, parece que os escritores preferem marcar um tom emotivo ou criar uma atmosfera de espontaneidade, reforçando a visão sentimental do mundo, visão que tende menos a selecionar do que a tudo aproveitar, menos a hierarquizar do que simplesmente a alinhar, sem interpretações reflexivas.
} 
Por outro lado, o predomínio da hipotaxe em um texto, caracterizada pelas subordinações, de acordo com Silva (1981, p. 122), exprime "uma visão do mundo que acredita na potência da razão humana, capaz de relacionar os fatos entre si". Desta maneira, as partes, representadas pelas orações, são subordinadas ao todo, ou seja, o texto, e essa organização se dá por meio da inteligência vinculada a uma "aplicação analítica e a busca de explicação" (SILVA, 1981, p. 123).

No ensaio "The Culture of Criticism" (1971), o teórico americano Hayden White já discutia os efeitos de sentido instaurados pelo uso da sintaxe paratática. Segundo o pesquisador, a organização paratática do discurso revelaria uma ruptura no impulso organizacional da linguagem. Segundo White (1971, p. 67),

O que os artistas e os pensadores inventivos desta era se rebelaram contra é exatamente o princípio de uma visão sintaticamente organizada, a consciência que requer a organização de uma realidade em relações de subordinação e de dominação. [...] As convenções paratáticas tentam resistir a qualquer impulso ao arranjo hierárquico de imagens e percepções e, como o radical da palavra parataxe indica, permite o "arranjar junto, lado a lado".

Em textos de João Gilberto Noll, encontramos ambas as modalidades, porém, em textos como "Refugiado" (2003, p. 322), "Vaga" (p. 80), "Ouvir águas" (p. 94), a linguagem paratática adquire uma maior relevância estilística. Quanto a "Sangue do Guaíba", como vimos, em vários segmentos do microconto o autor opta por utilizar uma linguagem que plasme a incongruência dos fatos e dos aspectos que compõem a realidade, dispondo as orações sem conexões rigorosas entre si, estabelecendo um nexo que é mais psicológico do que propriamente sintático. O próprio título do texto de Noll já aponta para essa incongruência, pois, como define o dicionário Houaiss da Língua Portuguesa, a palavra guaíba é empregada no sul do Brasil para designar uma região muito pantanosa. Deste modo, a escolha deste signo prefigura o caráter movediço, errôneo e instável das situações traumáticas experimentadas pelo narrador-protagonista.

Conforme podemos notar, mais do que sugerir ao leitor uma interpretação intelectiva dos acontecimentos que compõem a sua vivência, promovendo uma relação conceitual entre as idéias, organizando as seqüências narrativas de modo a criarem uma ordem familiar na tessitura dos fatos ou, em termos aristotélicos, desenvolvendo uma "ação completa formando um todo e de certa extensão", sendo este "todo" composto de 
princípio, meio e fim (ARISTÓTELES, 2005, p. 39), o narrador minimalista prossegue justapondo os elementos oracionais sem estabelecer relações hierárquicas entre esses termos, apenas aproveitando de maneira não seletiva as ocorrências envolvidas no instante ficcional e os pensamentos que brotam em sua mente e que, ao invés de esclarecer algo sobre o relato, acabam por confundir e problematizar ainda mais a situação.

Os microcontos de João Gilberto Noll, portanto, não sustentam o desenvolvimento fluente de interpretações analíticas, como temos observado em autores contemporâneos em língua portuguesa como José Saramago. Nos romances do autor português como, por exemplo, Ensaio sobre a cegueira (1995), percebemos um encadeamento sintático, que revela uma atitude interpretativa da realidade e um impulso de selecionar e organizar de modo racional e objetivo as idéias e os fatos: "A consciência moral, que tantos insensatos têm ofendido e muitos mais renegado, é coisa que existe e existiu sempre, não foi uma invenção dos filósofos do Quaternário, quando a alma mal passava ainda de um projecto confuso" (SARAMAGO, 2005, p. 26).

No brasileiro Noll, ao contrário, várias passagens de seus contos apresentam frases que não são conectadas entre si por relações interoracionais rigorosas. Os olhos do leitor percorrem essas orações curtas, pequenos fragmentos de realidade, e vão estabelecendo uma continuidade que é garantida não ao nível gramatical, mas no sentido do mero "esvaziamento da história" em um eixo horizontal imaginário (BARTHES, 1973, p. 26). O autor articula suas seqüencias narrativas, por exemplo, como em cortes cinematográficos. A realidade é representada em parcelas mínimas, em enquadramentos de imagens expressivas que, dispostas lado a lado, sugerem a fragmentação de uma experiência vivenciada em uma sucessão de quadros: "Apesar do estado das águas, entrei até os joelhos. E agora só restava assobiar. [...] Pouco a pouco o assobio amortecia tudo. A noite logo mais me acolheria. Para que sonhar?" (NOLL, 2003, p. 107).

Além do tom subjetivo que marca a linguagem de "Sangue no Guaíba", sugerida pelo enfoque nos pequenos movimentos e percepções do sujeito, a utilização da parataxe confere uma espécie de plasticidade a esses detalhes mínimos que compõem o universo ficcional. A sucessão de imagens captadas pelo narrador, as suas lembranças fragmentadas, seus sobressaltos e questionamentos, descritos em minúsculos blocos oracionais desconectados, colaboram para dar ao leitor a sensação de estar visualizando uma cena dissolvida em uma série de pequenas parcelas plásticas.

Conforme analisa Erich Auerbach (1971, p. 89), acerca das estratégias ficcionais empregadas em passagens de $A$ canção de Rolando, 
obra épica francesa do século XI, o emprego de uma sintaxe paratática denota a existência no texto de um "processo estacante, justapositor, que avança e retrocede aos empurrões, com o que se dissipam as relações causais, modais e até temporais". Essa estratégia narrativa, portanto, fragmenta o acontecimento em "uma série de parcelas pequenas e estáticas" (AUERBACH, 1971, p. 90), o que produz no texto a impressão de uma cena dissolvida em quadros justapostos, destituídos de uma conexão rigorosa. A sentença paratática revela, portanto, uma preocupação de ordem estética com a plasticidade e a energia dos gestos e das atitudes das personagens (AUERBACH, 1971, p. 99).

Auerbach (1971, p. 99) postula, ainda, que "os gestos do instante cênico" evocados pelas orações paratáticas podem transmitir "uma energia das mais marcantes e plásticas", pois "é esta energia dos gestos e das atitudes que é mirada, evidentemente, pela representação, ao subdividir os acontecimentos em muitas parcelas plásticas".

Em Noll, conforme podemos perceber, o narrador descreve uma seqüência de ações, coisas, sensações e pensamentos na qual ocorre um afrouxamento das relações conceituais e o que predomina é a sua abordagem de caráter subjetivo dos eventos que povoam sua experiência insólita. Esses pequenos "enquadramentos" dos gestos, situações e impressões descritos no texto são investidos de uma aura de confusão mental e, ao mesmo tempo, de beleza plástica que contribuem para a sugestão do dilema vivenciado pelo protagonista. Como as orações paratáticas obliteram as ligações de ordem causal, diluem os nexos temporais e solapam as relações explicativas entre as idéias, o relato do protagonista, assim estruturado, apresenta-se como um enigma que resiste ao preenchimento imaginário do apreciador.

Dessa forma, o sujeito que protagoniza esse relato é representado como um indivíduo confuso, desmemoriado, incapaz de estabelecer relações coerentes entre as ocorrências que precedem o instante ficcional fixado por seu relato e as circunstâncias presentes. Por essa razão, ao final do relato, o narrador parece desistir de tentar ordenar de maneira racional a complexidade dos fatos que compõem a sua experiência e restringe-se aos elementos palpáveis que o cercam como o rio, seu corpo submerso até a altura dos joelhos e, finalmente, seu assobio: "Pouco a pouco o assobio amortecia tudo" (NOLL, 2003, p. 107).

O texto promove um interessante jogo de sentidos a partir da ambigüidade do verbo "amortecer", que quer dizer "tornar como morto" e "diminuir o impacto, enfraquecer". Ao desistir de entender sua experiência a partir dos dados fragmentados fornecidos por suas lembranças precárias, o narrador elimina de modo gradual toda a reflexão e passa a enquadrar 
apenas os elementos imediatos que compõem o cenário ao seu redor. 0 assobio representaria a fase final desse processo de abdicação do entendimento, pois se trata de uma melodia orgânica, nascida de dentro do corpo como uma "melodia imprecisa", um mantra quase irracional, que precede a acolhida da noite. $O$ "assobio que amortecia tudo" prefigura, portanto, que o narrador busca um estado transitório de tranqüilidade (amortecer $=$ acalmar), mas, ao mesmo tempo, aponta para o abandono do tradicional impulso humano (amortecer $=$ ficar como morto) de impor uma organização cognitiva aos elementos propiciados pelo real e, a partir daí, interpretá-los. O narrador parece não dispor de mecanismos para superar o impasse no qual se encontra e, sentindo-se vulnerável e sem rumo diante da situação incompreensível, entrega-se à total incerteza, à morte ou falência do pensamento reflexivo, sugerida pelo emprego da palavra "noite" (perda da clareza, obscurantismo) em "A noite logo mais me acolheria". Ao final, o narrador indaga: "Para que sonhar?", indicando, por meio deste questionamento, que considera o fenômeno de sonhar, isto é, de conceber hipóteses imaginárias, seja consciente ou inconscientemente, um ato desnecessário ou mesmo inviável diante da impossibilidade de reduzir a complexidade do real a esquemas inteligíveis.

\section{RESUMO}

O objetivo do presente trabalho consiste em verificar as manifestações da identidade no contexto literário contemporâneo. Para tanto, selecionamos como corpus para esta pesquisa microcontos coligidos no livro Mínimos, múltiplos, comuns (2003), do escritor brasileiro João Gilberto Noll (1943). Em alguns dos textos reunidos nessa coletânea, Noll apresenta personagens que vivenciam situações angustiantes que as levam a experimentar crises de identidade. Dessa forma, é possível perceber que os protagonistas dos pequenos relatos de Noll configuram-se como representações imaginárias do sujeito pós-moderno, isto é, um sujeito que não dispõe de uma identidade definida, acabada, coerente, mas que está em um permanente processo de construção e de questionamento de sua própria identidade.

Palavras-chave: parataxe; indeterminação; identidade. 


\begin{abstract}
The objective of this work is to verify the manifestations of identity in the contemporary literary context. Therefore, we have studied the short stories by Brazilian writer João Gilberto Noll (1943-), encompassed in his book Mínimos, múltiplos, comuns (2003). In some of the texts collected in the volume, Noll presents characters that are subjected to tormented situations that make them experience identity crises. Thus, it is possible to infer that the protagonists of Mr. Noll's short stories represent imaginative figurations of the postmodern subject, that is, a subject whose identity is not defined, finished, coherent, but in constant process of construction and questioning.

Key-words: Parataxis; Indeterminacy; Identity.
\end{abstract}

\title{
REFERÊNCIAS
}

ARISTÓTELES. Arte poética. Tradução de: Pietro Nassetti. São Paulo: Martim Claret, 2005.

AUERBACH, Erich. Mimesis: A representação da realidade na literatura ocidental. Tradução de: George Bernard Sperber e Suzi Frankl Sperber. São Paulo: Perspectiva, 1971.

BARRENTO, João. Mas resta ainda (Prefácio). In: HATHERLY, A. Rilkeana. Lisboa: Assírio \& Alvim, 1999. p. 11-19.

BARTH, John. A Few Words About Minimalism. In: Further Fridays: Essays, Lectures, and Other Nonfiction (1984-94). Boston: Little, Brown and Company, 1995. p. 64-74.

BARTHES, Roland. Introdução à análise estrutural da narrativa. In: .et al. Análise estrutural da narrativa. 3. ed. Petrópolis: Vozes, 1973.

BIRKERTS, Sven. The Struggle for the Soul of the Sentence. The Wilson Quarterly, v. 25, 4, p. 68, Autumn, 2001.

BOSI, Alfredo. História concisa da Literatura Brasileira. 36. ed. São Paulo: Cultrix, 1999.

BRASIL, Ubiratan. Os instantes ficcionais de João Gilberto Noll. O Estado de São Paulo. Caderno 2, 27 jul. 2003. Disponível em: <http://www.joaogilbertonoll.com.br/estudos.html>. Acesso em: 13/03/2004.

BRIDI, Marlize V. Modernidade e pós-modernidade na ficção portuguesa contemporânea. São Paulo: USP, 1999.

CEVASCO, Maria Elisa. Para ler Raymond Williams. São Paulo: Paz e Terra, 2001.

EAGLETON, Terry. The Illusions of Postmodernism. Oxford: Blackwell, 1997.

ECO, Umberto. Obra aberta: forma e indeterminação nas poéticas contemporâneas. Tradução de: Giovanni Cutolo. São Paulo: Perspectiva, 1969.

HALL, Stuart. A identidade cultural na pós-modernidade. Tradução de: Tomaz Tadeu da 
Silva e Guacira Lopes Louro. 7. ed. Rio de Janeiro: DP\&A, 2002.

HASSAN, Ihab. The Postmodern Turn: Essays in Postmodern Theory and Culture. Columbus: Ohio University Press, 1987.

JAMESON, Fredric. Pós-modernismo: a lógica cultural do capitalismo tardio. 2. ed. Tradução de: Maria Elisa Cevasco. São Paulo: Ática, 2000.

MCCAFFERY, Larry. The Fictions of the Present. In: ELLIOTT, E. (Ed.). Columbia Literary History of the United States. New York: Columbia University Press, 1988. p. 1161-1177.

NIETZSCHE, Friedrich Wilhelm. Além do bem e do mal: prelúdio a uma filosofia do futuro. Tradução de: Paulo César de Souza. São Paulo: Companhia das Letras, 2005.

NINA, Cláudia. A literatura vive um renascimento: o escritor gaúcho João Gilberto Noll lança um romance inspirado em sua experiência como estrangeiro. Jornal do Brasil, 02 nov. 2002. Disponível em: <http://www.joaogilbertonoll.com.br/estudos.html>. Acesso em: $13 / 03 / 2004$.

NOLL, João Gilberto. Mínimos, múltiplos, comuns. São Paulo: Francis, 2003.

ROSENFELD, Anatol. Literatura e personagem. In: et al. A personagem de ficção. 9. ed. São Paulo: Perspectiva, 1998. p. 10-49.

SACCONI, Luís A. Nossa Gramática: teoria e prática. 20. ed. rev. e atual. São Paulo: Atual, 1994.

SARAMAGO, José. Ensaio sobre a cegueira. São Paulo: Companhia das Letras, 2005.

SILVA, Antônio Manoel dos Santos. Análise do texto literário: orientações estilísticas. Curitiba: Criar Edições, 1981.

SILVA, Tomaz Tadeu da (Org.). Identidade e diferença: a perspectiva dos Estudos Culturais. 4. ed. Petrópolis-RJ: Vozes, 2005.

TREECE, David. Prefácio. In: NOLL, J. G. Romances e contos reunidos. São Paulo: Companhia das Letras, 1997. p. 7-16.

VILLAÇA, Nízia. Paradoxos do pós-moderno: sujeito \& ficção. Rio de Janeiro: UFRJ, 1996.

WHITE, Hayden. The Culture of Criticism. In: HASSAN, I (Ed.). Liberations. Middletown, Connecticut: Wesleyan University Press, 1972. p. 55-69. 